$\stackrel{W}{N}$

Global Journals Inc

(2)

\title{
A Guide towards Building Effective, Metrics-Driven and Mathematical Sales Segmentation Models for an Enterprise B2B SaaS Business
}

\author{
By Venketesh Iyer \& Rahul Peravali
}

University of California

Abstract- The paper's goal is to help B2B SaaS companies attain two primary goals - 1. Leverage best-in-class business firmographic data for building territory segmentation models 2 . Balance the models against the most effective sales metrics, and 3. Understand and optimize for territory disruption year over year due to change in the scale of business. In the paper, we build a model based on the most fundamental building blocks of any SaaS business. The analytical model helps the sales operations, revenue operations and sales departments understand the main drivers of territory disruption and, build balanced territory segments to ensure equitable financial targets for sales reps.

Keywords: sales operations, sales strategy, analytics, territory operations, segmentation, territory carving, sales planning, marketing, customer relationship management, data modeling, data quality, B2B, saas.

GJMBR-E Classification: JEL Code: H19

Strictly as per the compliance and regulations of:

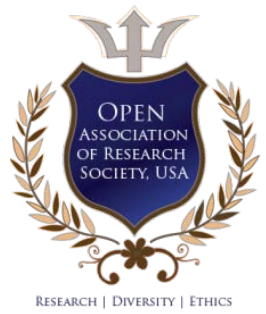

(C) 2020. Venketesh lyer \& Rahul Peravali. This is a research/review paper, distributed under the terms of the Creative Commons Attribution-Noncommercial 3.0 Unported License http://creativecommons.org/licenses/by-nc/3.0/), permitting all non-commercial use, distribution, and reproduction in any medium, provided the original work is properly cited. 


\title{
A Guide towards Building Effective, Metrics- Driven and Mathematical Sales Segmentation Models for an Enterprise B2b SaaS Business
}

\author{
A Practical Guide towards Building an Effective, Metrics-driven Sales Segmentation \\ Model and Analyzing Organizational Shift for an Enterprise B2B SaaS Business
}

\author{
Venketesh lyer ${ }^{\alpha} \&$ Rahul Peravali ${ }^{\sigma}$
}

\begin{abstract}
The paper's goal is to help B2B SaaS companies attain two primary goals - 1. Leverage best-in-class business firmographic data for building territory segmentation models 2 . Balance the models against the most effective sales metrics, and 3. Understand and optimize for territory disruption year over year due to change in the scale of business. In the paper, we build a model based on the most fundamental building blocks of any SaaS business. The analytical model helps the sales operations, revenue operations and sales departments understand the main drivers of territory disruption and, build balanced territory segments to ensure equitable financial targets for sales reps.
\end{abstract}

Keywords: sales operations, sales strategy, analytics, territory operations, segmentation, territory carving, sales planning, marketing, customer relationship management, data modeling, data quality, B2B, saas.

\section{Sales Segmentation Rationale}

S ales segmentation entails mapping the most experienced and talented sales teams to the specific customer segments they are suited for and thereby establishing distinct marketing techniques to those cohorts. It involves:

1. Identifying segments of your existing and potential customer base with 'like' attributes i.e., industry, geography, size and, allowing your company to maximize its return on investments by tailoring efforts to specific groups.

2. Identifying the most efficient distribution channel.

3. Aligning sales/partner talent based on the complexity of the products and the needs of the segment.

The key goals of territory segmentation are to reduce expenditures made to market to clients who do not want or need your services or products, elevate customer experience and loyalty and minimize attrition.

Author $\alpha$ : University of California, Berkeley.

e-mail: venketesh_iyer@berkeley.edu

Advisor: Wasim Azhar

\section{Scope Business Model}

The scope (business model) that the below strategy best aligns with is B2B direct subscription product sales. The business reflected in the paper is primarily an Enterprise SMB play i.e., the largest of the revenue comes from the smallest of the businesses. The scope of sales territory planning outlined below is limited to certain organizational groups: core and specialist sales teams, sales operations, corporate finance, and any other teams that directly influence sales territory allocation and revenue measurement. While sales have a significant role to play in the curation of the company's GTM strategy - it typically rests within the wheelhouse of sales operations. The revenue and HR organizations contribute heavily to the planning exercise.

\section{ili. Segmentation Fundamentals}

The larger the customer, the more complex the sales cycle. Also, the higher the segment, the lesser the number of customers per sales rep in general, resulting in a pyramid. The largest of the customers are more geographically distributed, and hence one sales rep is often supported by a few local Sales Development Reps (SDRs) / Business Development Reps (BDRs). However, one thing to note here is that coverage also might depend on how important/strategic this customer is and how large of a sales force the company can afford to have. Sometimes companies will have a dedicated sales team serving a single customer depending on their size and revenue share.

There are three broad options for sales territory segmentation.

Option 1 | Geographic Segmentation

- Minimizes travel cost

- Minimizes confusion i.e., One sales rep per customer

Typically implemented where co-selling is needed in diverse geographical areas, and a territory overlap is key, when the product line is narrow, and 
differentiation is lesser, variety amongst buyer needs is less.

\section{Option 2 | Product Segmentation}

- Product expertise

- $\quad$ Minimize the interface for other support engineering teams

Typically implemented where delivery is a sales success metric and product lines are wider and more complex.

\section{Option 3 | Market / Customer Segmentation}

- $\quad$ Sales rep brings in domain knowledge.

- Ability to pitch an overall solution to suit the industry needs

They are typically implemented where specialized customer orientation knowledge is needed and when the market/industry is rapidly shifting.

The segmentation modeling outlined below is primarily anchored on Option 3 | Market / Customer Segmentation.

The following set of best practices are written with a lens of data that is housed in a CRM environment. The business model that the below strategy best aligns with is B2B direct subscription product sales. The scope of sales territory planning outlined below is limited to certain organizational groups - core and specialist sales teams, sales operations, corporate finance and any other teams that directly influence sales territory allocation and revenue measurement. While sales have a significant role to play in the curation of the company's GTM strategy - it typically rests within the wheelhouse of sales operations. The revenue and HR organizations contribute heavily to the planning exercise.

Assuming the data quality of an organization is optimal, and the sales data is "trusted" and "certified", the two most critical elements of conducting territory segmentation at scale are:

- Identification of the fundamental data attributes that are reflective of the company's go-to market strategy

- Formulating rules to segment customers into "cohorts", on top of this "trusted" data

Identification of the fundamental data attributes that are reflective of the company's go-to market strategy.

Every B2B company has a system of record of its customers i.e., businesses. This exercise entails identifying the core data attributes or fields (in the CRM world) that are integral to the company's GTM strategy. For example, a company that sells its product globally, across several industries could have the following attributes of its customer records as building blocks of segmentation:

- Geographical.

- Vertical or Industry or Category of the customer.
- The materiality of the customer to the company Employees (reflecting size), Seats/Licenses (in case of a subscription model), Revenue (reflecting business), Deal Pipeline (reflecting potential).

- Product adoption.

Formulating RULES to segment customers into "cohorts", on top of this "trusted" data

Doing this for the first time is the hardest! It requires numerous conversations and pilots across the sales organization to build trust that "data" can replace some element of "intuition" in territory segmentation. It requires various permutations and combinations of choosing the right attributes and choosing the right level.

\section{Examples}

1. One can stay high level by creating a cohort of a combination of country and revenue size (based on some sizing exercises). E.g.: US-Large Enterprises, UK-Mid Enterprises, India-SMB

\section{$\mathrm{OR}$}

2. One can create many granular cohorts with a combination of country, state, employee count (based on some sizing exercises), vertical, subvertical and hero product adoption. E.g.: Take a company with three distinct product lines - $\mathrm{Pa}, \mathrm{Pb}$, PC.

a. CA-Quebec-SMB- A sales leader is covering the Quebec province for all small businesses.

b. US-Oregon Washington-Large-Consumer ProductsFood-Pa- A Pa specialist sales representative covering the large-scale Pacific Northwest food industry.

It is very challenging to get this right in the first year and it is an iterative process for subsequent cycles. BUT it is one of the most efficient techniques that will reward the organization in the longer term and get you a step closer towards an efficient sales planning cycle.

\section{Analytical Modeling}

There are TWO pillars, a Sales Operations team must in parallel consider:

1. Team- Ensure that each sales rep, frontline manager and leader is successful in headcount management and span of control.

2. Business- Ensure each sales segment defined, is relatively balanced for the revenue potential and open pipeline per sales rep.

Let us take a closer look at the two pillars above.

a) Team

A successful sales operations team identifies the selling roles needed for the next year and then outlines the core sales rep mapping to each level. A model can look something like below - Segment A being 
a cohort of the largest customers (could be by either employee size or revenue size):

The chart below outlines the ratio of AEs to specific roles within the company and contrasts the same between the current and next year. An AE-Sales Manager ratio of 4:1 means - 1 Manager oversees 4 AEs. An AE-Solution Engineer ratio of 6:1 means - 6 AEs are supported by 1 SE.

\begin{tabular}{|c|c|c|c|c|c|c|c|c|}
\hline & \multicolumn{2}{|c|}{ AE : Sales Manager } & \multicolumn{2}{|c|}{ AE : Solution Engineer } & \multicolumn{2}{|c|}{ AE : Product Specialist A } & \multicolumn{2}{|c|}{ AE : Product Specialist B } \\
\hline & Current FY & Next FY & Current FY & Next FY & Current FY & Next FY & Current FY & Next FY \\
\hline Segment A & $4: 1$ & $5: 1$ & $8: 1$ & $6: 1$ & $2: 1$ & 1:1 & $3: 1$ & $2: 1$ \\
\hline Segment B & $6: 1$ & $5: 1$ & $5: 1$ & $6: 1$ & $4: 1$ & 3:1 & $4: 1$ & 4:1 \\
\hline Segment C & $8: 1$ & $6: 1$ & $6: 1$ & $5: 1$ & $6: 1$ & $6: 1$ & $5: 1$ & $4: 1$ \\
\hline Segment D & $3: 1$ & $4: 1$ & $5: 1$ & $5: 1$ & $8: 1$ & $7: 1$ & $9: 1$ & $7: 1$ \\
\hline
\end{tabular}

b) Insight: As you can see above, the sales rep to manager mapping is fairly balanced across all segments to ensure that the frontline manager is successful and has equitable accountability across the board. Also note the Product Specialist mapping. A single product specialist can offer expertise to multiple sales reps; however, the scale of such support minimizes as the segment gets larger. Realistically, a product specialist can support max. 1-2 enterprise sales reps given the sheer complexity of dealing with larger organizations.

\section{BUSINESS}

There are many fundamental metrics any sales operations personnel should understand before diving into the Analytical Modeling part.

- Account Executives (AEs) / Client Partners / Sales Representative - The lead AE running the deal

- Account- A Business/entity

- Customer- A Business/entity with an active contract; includes free license and revenue-generating accounts.

- Book of Business- List of accounts/customers on which the sales representative is the primary owner (AE).

- Quota- Annual/Quarterly/Monthly revenue target for an $\mathrm{AE}$ to attain; a reflection of $\mathrm{AEs}$ on their job performance.

- Seasonality- Scaling factor to set quotas quarterly based on seasonal trends. An annual quota is seldom divided straight by four to compute the quarterly quota. For example, in some businesses, Q1 is the slowest. The Q1 quota might be the lowest of all and the Q4 might be the highest of all.

- Quota Attainment- A percentage computed based on $\$$ value (sum of opportunity amount) of the deals closed by an $\mathrm{AE}$ relative to their Quota. Quota attainment can be computed monthly, quarterly or annually - typically quarterly or annually. For e.g., If an $\mathrm{AE}$ with $\$ 1 \mathrm{M}$ annual quota, who closes $\$ 900 \mathrm{k}$ is at $90 \%$ attainment.

- ACV (Subscription Business Model) or RevenueTarget total $\$$ value of open deals that are closed and won - computed over a time period.

- Growth- ACV - Year over Year \% comparison of the metric across timeframes.

- Open Pipeline (\$) - Total $\$$ value (sum of opportunity amount) of open deals that are not dead, won or closed.

- AOV (Annual Order Value) - Annualized ACV

- $T T M$ ACV- ACV over the past/trailing 12 months at any point in time

- Pipeline Generated (PG)- Total \$ value (sum of opportunity amount) of open deals generated at a specific point in time, regardless of their status (open/dead/closed/won/lost).

- Bookings Potential (BKP) - The full ACV potential of this customer assuming 100\% penetration. Note that this is different from Total Addressable Market (TAM) which is assumed $100 \%$ penetration into the entire industry/market.

Let us begin by drawing out the current state of the business. Assume that the cohorts are named SUMMIT, ENTR (Enterprise), MID (Midsize), SMALL, TINY. The rules behind each cohort's definition are written next to it. A handful of key measures to understand how balanced the cohorts are for the current state of the business and potential business, are all stacked next to each segment. If contiguous segments are off-balance, the RULES are the first place to calibrate and adjust. 
Let us look at an example below

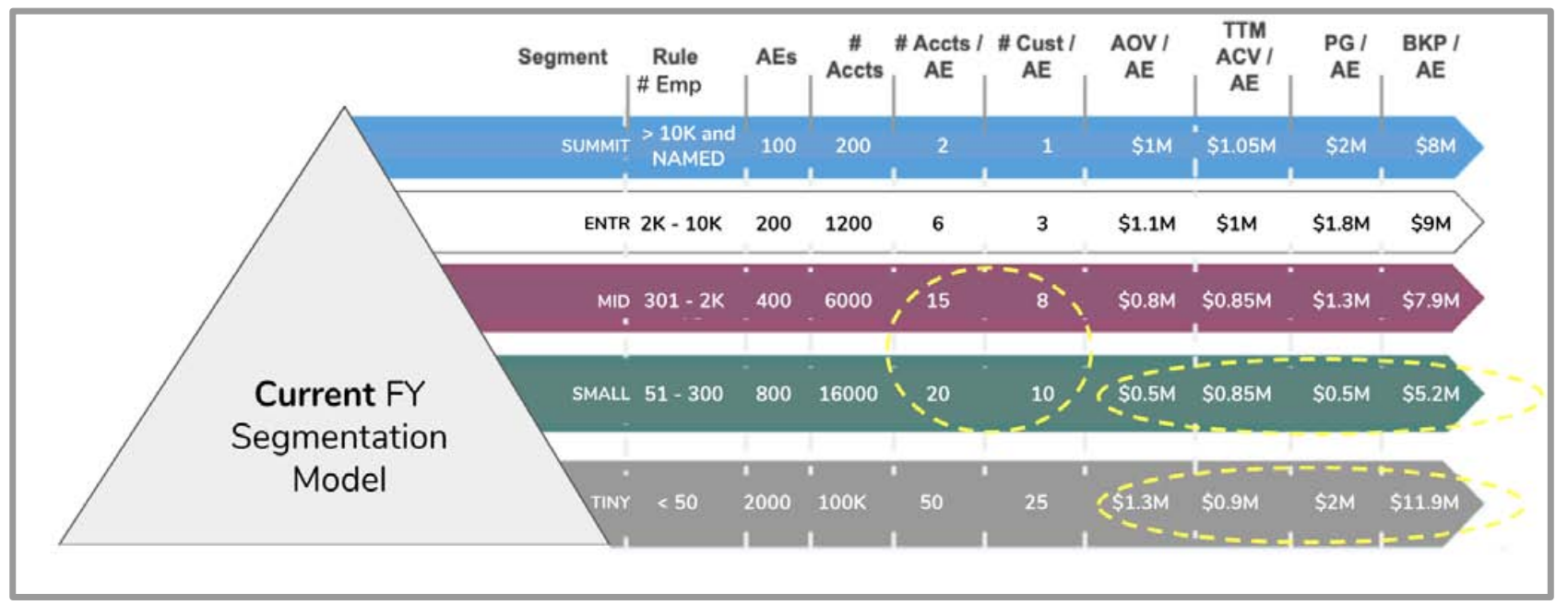

\section{Pre-Segmentation}

a) Observations

One could see that

1. The difference in the book of business (\#) per $A E$ is the least between MID and SMALL, but the AOV, PG and, BKP sharply decline.

2. The jump in the average business (\$) as well as potential (\$) per AE (AOV, PG and, BKP) is large between SMALL and TINY whereas they are balanced for all segments.

3. The TTM ACV/AE remains the same which indicates that the massive spike is attributed towards the later part of the trailing 12 months i.e., very recent.

\section{Vil. Conclusions}

The above observations allude to a few key takeaways

1. The smallest segment TINY carries the largest weight on the AEs. Typically, Account Executives in a small business segment are either at an early stage of their career or do not prefer having complex implementation conversations which entail high dollar value contracts.

2. The SMALL segment has experienced some attrition given the book of business is similar but net revenue faces a sharp dip compared to MID.

a) Action

Our conclusions logically point to a few key next steps

1. Expand the lower bound of the SMALL segment i.e., shift inwards the upper bound of/shrink the TINY segment so that more revenue flows into the SMALL segment. This reduces the scale of the jump between SMALL and TINY.

2. Additionally, expand the upper bound of the SMALL segment to minimize the book of business distribution in the MID segment, thereby normalizing the change per segment.
1. Transfer more headcount from SMALL to TINY, to balance out the book of business and potential between the three segments - an important lever from the "TEAM" pillar described earlier. RED FLAG: Transferring AEs to a lower segment can be often perceived as a Demotion. As a result, this option shall not be feasible.

2. Instead, we hire aggressively in the TINY segment.

\section{Vili. Segmentation}

a) Here is what we are going to do

1. Change the segment line definitions for SMALL, TINY and, MID to below:

a. TINY: $<40$

b. SMALL: $41-325$

c. MID: $326-2 \mathrm{k}$

d. Make HC changes:

e. Hire 300 additional AEs (extra 15\% on the base $2000 \mathrm{HC}$ ) for the TINY segment.

f. Per the ratios described in the TEAM section, hire additional managers or shift coverage necessary (this is out of the scope of this paper).

b) A few assumptions

- Assume the same Customer to Account ratio for simplicity

- Linear impact of \# accounts on AOV, PG, TTM and BKP

- Uniform net (incl. attritions) HC growth of $15 \%$ in all segments except TINY where HC will grow 25\% intentionally per the segmentation process and MID + SMALL where there is no net hiring (except for backfills due to the segment line shrinking and the need to maintain balanced patches).

- Assume the industry standard of $20 \%$ organic net (including attritions) YoY growth in number of Accounts and Customers (to keep ratios the same) 
- Assume industry standard of $30 \%$ organic net (including attritions) YoY growth in business i.e., \$ AOV, PG, TTM and BKP except for TINY which is assumed to grow at $40 \%$ (the smallest of the

\section{iX. Impact and Preliminary Disruption Analysis}

a) Before $\mid A O V$ Per $A E$

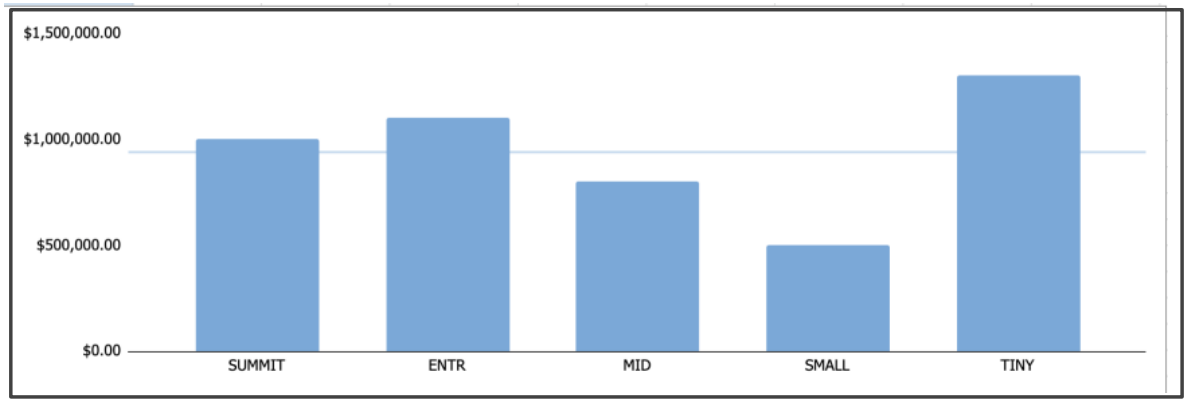

b) After $\mid$ AOV Per AE: More Uniform

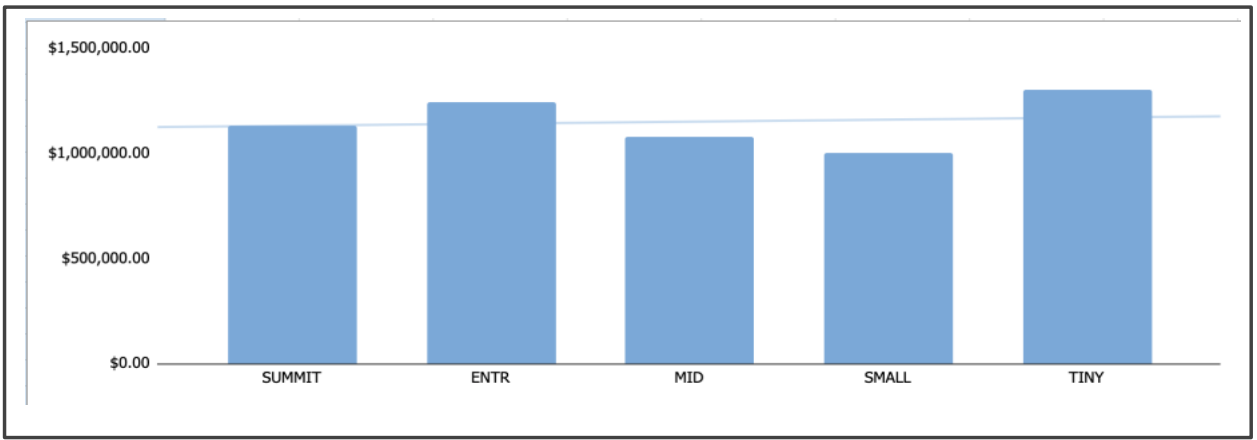

c) Before | Book of Business Per AE: Sharp Jump

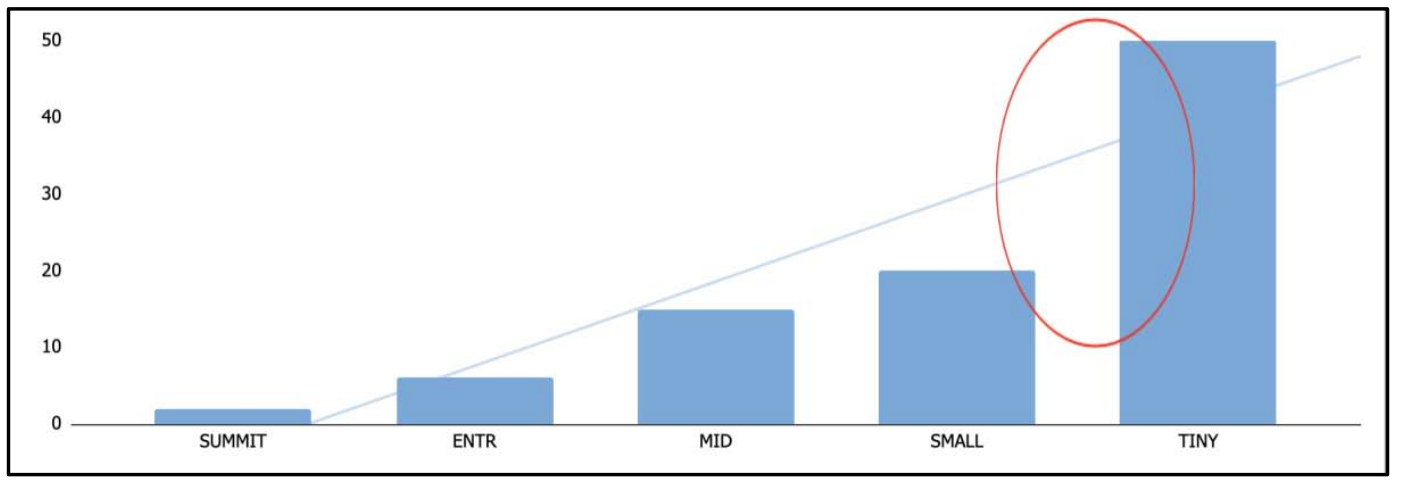

d) After | Book of Business Per AE: Normalized Jump

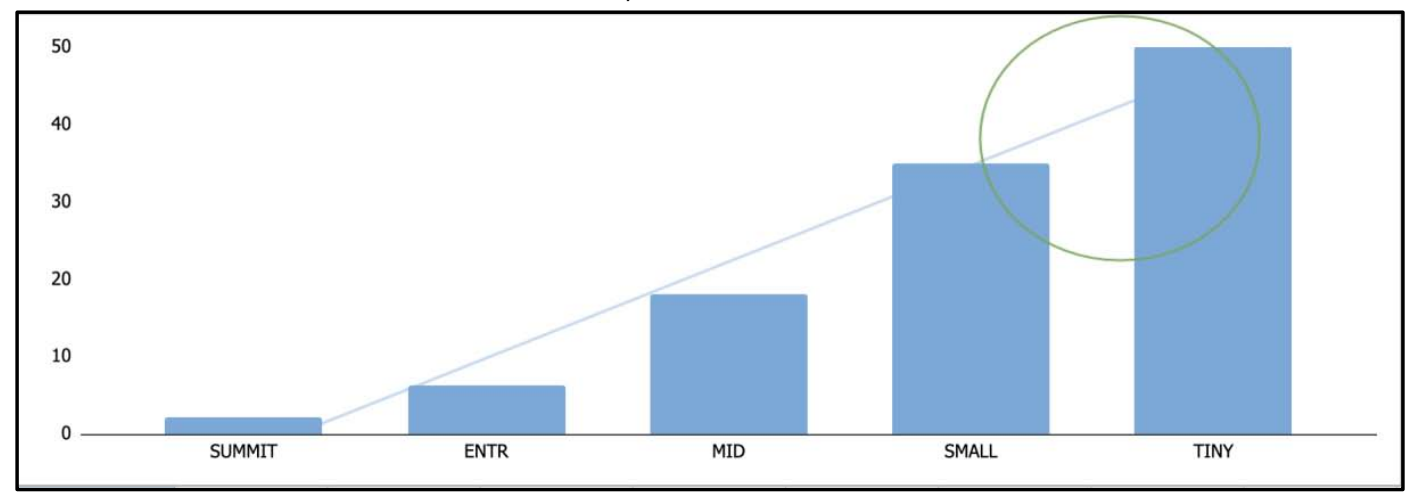




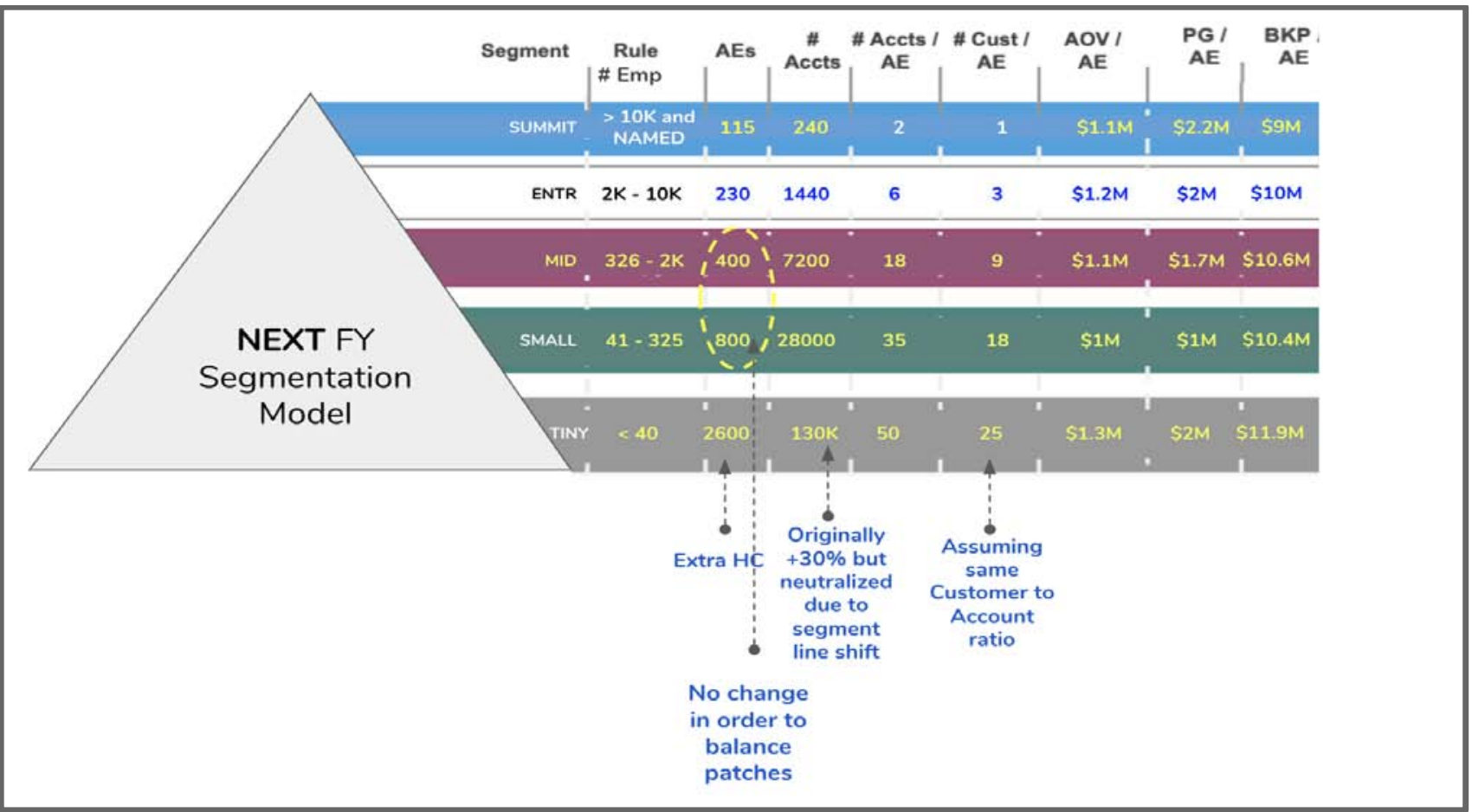

\section{f) Shift in Trend}

Lastly, we review the Revenue Distribution by DEAL BAND to see if the trends are shifting towards the company catering to more mature businesses.

Let us define a couple of key terminologies here:

Deal Size: Typically, Deal Size $=$ Price Per Seat $\mathrm{x}$ Number of Seats. One "deal" could be a combination of a few sub deals/opportunities, but the lump sum is factored into computing a deal size.

Deal Band: A Deal Band is a bucket computed based on the size of the deal for a specific customer.

\section{g) Current FY v/s Next FY Distribution}

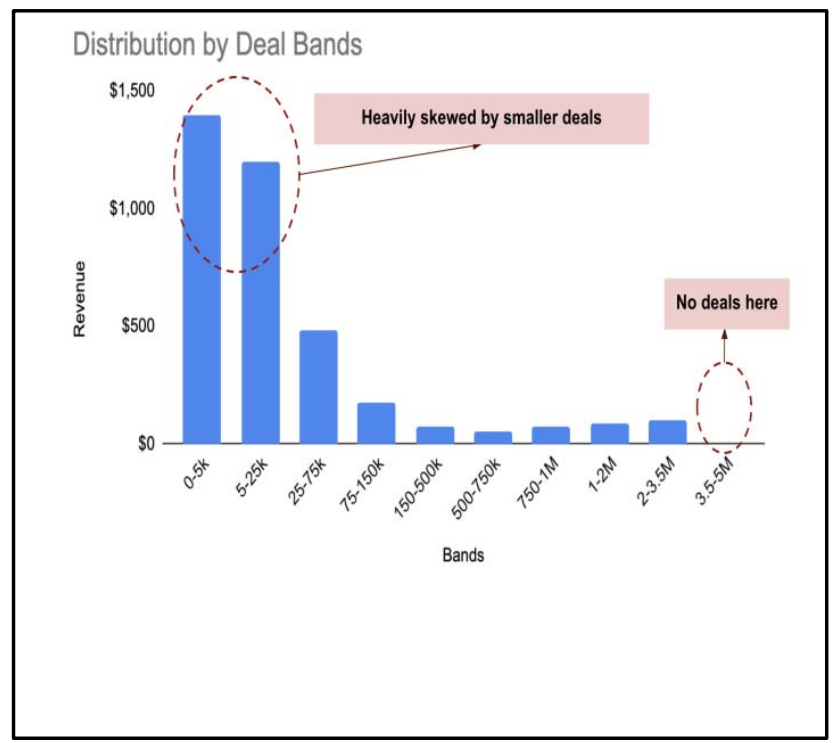

Sometimes AEs are provided additional incentive pay or SPIFs (Special Performance Incentive Fund Funds) for closing large deals i.e., towards the higher side of the deal band. Let us say a company has a wide range of deals starting up to $\$ 5 \mathrm{M}$. One would then start grouping deals into a dollar value bucket to build distribution of deals. A logical demarcation is made to define cut-off points (lower and upper bounds) for each deal band. Such a demarcation is typically made on the basis of value provided to each segment.

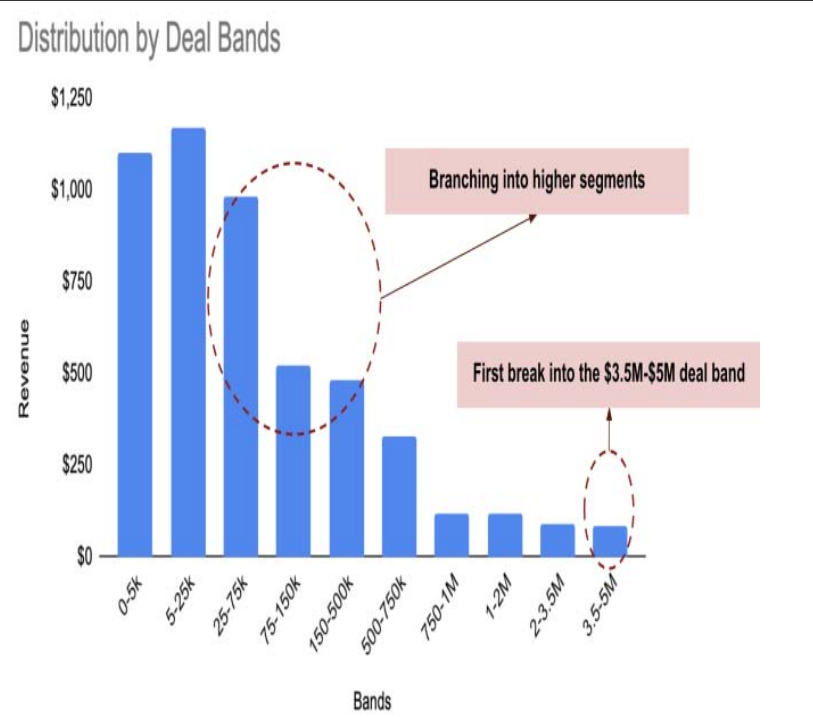


Based on the change in the segmentation, a detail ed distribution, by segment, by deal band will compare like:

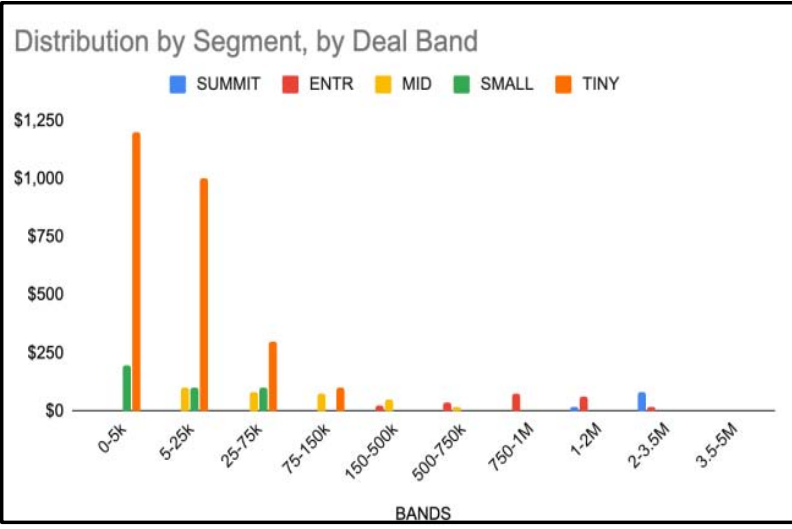

h) Endnote | Conclusion

- Based on the above distribution, we record a $38 \%$ YoY growth and a key insight that the business is shifting towards capturing larger deals.

- The business is not just an SMB play anymore; the company won its first large deal $>\$ 3.5 \mathrm{M}$, resulting in a brand-new deal band of $\$ 3.5 \mathrm{M}-5 \mathrm{M}$.

- With all of the above, the primary goal of sales segmentation is to balance simplicity with the everincreasing momentum of the sales organization.

- $\quad$ The larger the company or the faster the company grows, the more convoluted the sales operations process is; such complexity can often depend on the pricing and packaging model, breadth of product offerings, size of the sales organization, revenue recognition process, approval layers, reporting needs, forecasting needs and more.

- Data-driven sales segmentation is not only an effective way to ensure fairness and equitable treatment for the sales organization, but also a very effective way to identify where the company is shifting.

\section{Bibliography References}

1. Pearson, Owen | What is Sales Segmentation Retrieved from: https://smallbusiness.chron.com/ sales-segmentation-32032.html\#: : :text=Sales\%20 segmentation\%20is\%20the\%20process, purchasing \%20your\%20products\%20or\%20services

2. Nguyen, Tien Anh | Customer Segmentation: A Step By Step Guide For B2B | Retrieved from: https://openviewpartners.com/blog/customer-segm entation/\#.XuOtPJNKhQI

3. Insycle CRM Data Operations | Why Effective Customer Segmentation is Critical for Driving Growth | Retrieved from: https://blog.insycle.com/e ffective-customer-segmentation

4. Smith, Gary | 2 Account Segmentation Hacks to save You Time and Money | Retrieved from:

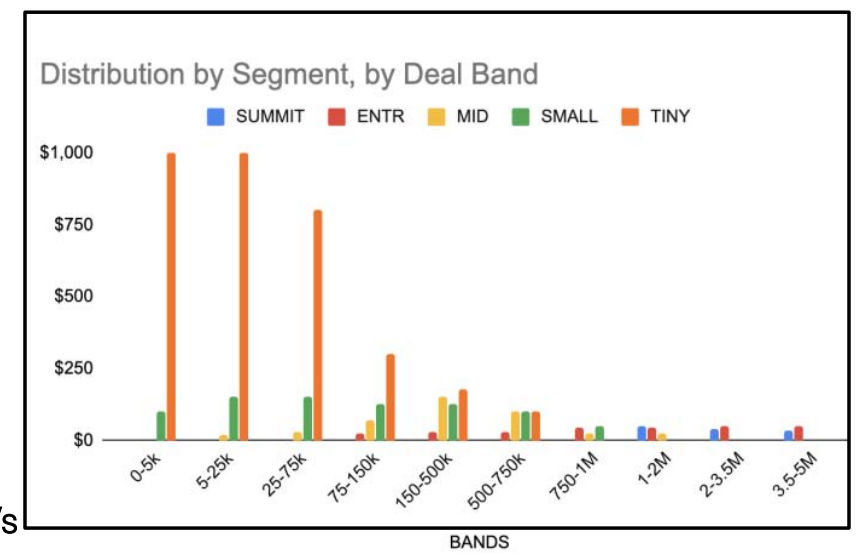

https://garysmithpartnership.com/account-segment ation/

5. Reddy, Susmitha| Top Tips To Improve Sales force Data Quality | Retrieved from: https://cloudintegrate.com/top-tips-to-improve-salesforce-dataq uality/

6. Mulder, Patty | Ladder of Inference | Retrieved from:https://www.toolshero.com/decision-making/la dder-of-inference/

7. Iyer, Venketesh | The Four Most Crucial Elements of Conducting Sales Territory Segmentation at Scale | Retrieved from: https://globaljournals.org/ GJMBR Volume 20 Issue 3 Version 1.0 June 2020

8. Iyer, Venketesh; Zhang, Dan | Creating a Curated Lens: Your Sales Analytics Framework| Retrieved from: https://people.ai/blog/creating-a-curated-lensyour-sales-analytics-framework/ 